\title{
Change in Preoperative Nervousness: A Randomized Controlled Trial in Gynecological Cancer Patients
}

\author{
Marianne K. Thygesen ${ }^{1,2 *}$, René De Pont Christensen ${ }^{3}$, Lone Hedemand ${ }^{1}$, Ole Mogensen ${ }^{1,2}$ \\ ${ }^{1}$ Institute of Clinical Research, Faculty of Health Sciences, University of Southern Denmark, Odense, Denmark \\ ${ }^{2}$ Department of Obstetrics and Gynaecology, Odense University Hospital, Odense, Denmark \\ ${ }^{3}$ Research Unit of General Practice, University of Southern Denmark, Odense, Denmark \\ Email: *marianne.thygesen@rsyd.dk
}

Received 30 December 2015; accepted 2 February 2016; published 5 February 2016

Copyright (C) 2016 by authors and Scientific Research Publishing Inc.

This work is licensed under the Creative Commons Attribution International License (CC BY). http://creativecommons.org/licenses/by/4.0/

(c) (i) Open Access

\begin{abstract}
Patients are often nervous prior to surgery and females might suffer the most. Increased nervousness needs attention as it can negatively affect postoperative recovery. Support from nurses, i.e. being present, attentive, empowering and helpful to the patient, and talking about what is on the patient's mind, might help to reduce nervousness. However, there is a lack of evidence as to the ideal level of attention and resources to reduce preoperative nervousness. The objective of the current study was to compare a range of care combinations with standard care to female patients prior to sedation and cancer surgery primarily on difference in change in nervousness from admission until sedation before cancer surgery, measured on a Visual Analouge Scale. Using simple randomization and numbers in sealed envelopes, adult gynaecological patients scheduled for open cancer surgery were allocated to care provided by a nurse anaesthetist and: A) a surgical nurse, B) no additional care, C) a known nurse , and D) a relative. Only the statistician was blinded. The trial stopped when the calculated numbers were included. In the full analysis set, compared to standard care $A)(n=61)$, we observed the following mean changes and [95\% confidence intervals]: $B)(n=65) 1.05$ [CI: 0.298 to 1.794] with $p=0.006, \mathrm{C})(\mathrm{n}=61):-0.38$ [-1.140 to 0.385$]$ with $p=0.330, \mathrm{D})(\mathrm{n}=71): 0.23$ [-0.498 to 0.967$]$ with $p=0.528$. Female cancer patients will benefit from supportive care by a surgical nurse from the time of arrival on the operating ward plus supportive care from a nurse anesthetist from 5 10 minutes after entering the operating ward. It is not recommended at any time to rely fully on the support of relatives. The effect on adults of preoperative painful procedures and patients' time alone on the operating ward should be further investigated.
\end{abstract}

\section{Keywords}

Anxiety, Cancer, Perioperative Care, Randomized Controlled Trial, Women's Health

\footnotetext{
${ }^{*}$ Corresponding author.
}

How to cite this paper: Thygesen, M.K., De Pont Christensen, R., Hedemand, L. and Mogensen, O. (2016) Change in Preoperative Nervousness: A Randomized Controlled Trial in Gynecological Cancer Patients. Health, 8, 219-229. 


\section{Introduction}

Preoperative nervousness and anxiety are common [1]-[8]. Anxiety is "a feeling of worry, nervousness, or unease about something with an uncertain outcome" [9] and nervousness is found to express essential elements of anxiety [3] [10]. Increased preoperative anxiety or nervousness can lead to deterioration in the patient's postoperative situation, e.g. increased pain, decreased mood, or negatively affected patient satisfaction [11]-[14]. However, we do not know the ideal level of attention and resources that should be made available to alleviate this situation. In meeting the challenges involved in sedation and surgery, patients will ideally be provided with suitable techniques aimed at helping them to manage, or decrease, their anxiety or nervousness. Many such techniques exist [4] [5] [12] [15]-[19]. One technique is the provision of support, i.e. for a nurse to be present, attentive, empowering and otherwise helpful towards the patient and to talk about what is on the patient's mind. Such support could be of a therapeutic nature, and gives the patient the opportunity to initiate a close bond with the healthcare professional [1] [15] [20] [21]. However, the time spent on the operating ward might be too short for patients to create a close psychological bond and obtain the optimum benefit from it [5]. Multiple studies have tested interventions to reduce preoperative anxiety or nervousness. A literature review of anxiety-reducing techniques primarily found tests of premedication and distraction and concluded that anxiety management was "dominated more by the desire for clinical efficiency than by effective individual requirements" [4]. A more active and less helpless attitude on the part of patients might be of the most benefit to them [4] [22]. Recent systematic reviews of patient education find information techniques to be promising but not convincing [17] [23] and, again, the authors emphasize the importance of meeting individual support needs. Others found the supportive element and the patient-nurse relationship to be important [1] [24], as this might allow healthcare professionals to choose appropriate techniques. Close relatives might also be a valuable support for patients before anesthesia, as they already know each other and often have affectional bonds, and relatives might intuitively support the patient in the way best suited to the patient [20] [25]. Moreover, from the patients point of view, there might be differences between sex in preoperative anxiety and preferences for support, and women might suffer the most [7] [18] [26]-[28]. Therefore, the objective of this research was to investigate the effectiveness of different care combinations delivered by nurses and relatives to adult females awaiting cancer surgery, and we had chosen the gynecological field. Standard care comprised situational support delivered by a nurse anesthetist in combination with a surgery nurse and we aimed to test the hypothesis: Situational support before sedation and surgery by a nurse anesthetist alone or in combination with a relative or a nurse known to the patient will prove superior to standard care, primarily with regard to a reduction of patient nervousness before anesthesia and, secondarily, with regard to global patient satisfaction before discharge.

\section{Methods}

\subsection{Trial Design and Participants}

A study with simple randomization was conducted in a large university hospital in Denmark that serves 1.2 million people. Patients were included in this study if they were offered open surgery for gynecological cancer, could communicate in Danish, and accepted the ward standard of anesthesia without anxiolytic premedication. Moreover, participants should have an adult close relative who agreed to accompany the patient to the operating ward on the day of surgery, if necessary. Exclusion criteria were permanent mental disability and those under the age of 18 . No changes were made after commencement.

\subsection{Interventions and Standard Care}

All the participating nurses were educated in Denmark and had a bachelor in nursing minus three months. No special training was performed in regard to this study. They all worked with gynecological cancer care and had the intention to support patients in the best possible way during the perioperative period. They used their resources and competences in interaction with individual patients; i.e. they were present, attentive and helpful, and chatted at the patient's convenience. Moreover, they used additional anxiety-reducing strategies appropriate to the immediate situation: informed (provided factual information), predicted (predicted a better outcome than what the patient expected), empowered (gave information about a matter of course before explaining options available for action, and eventually encouraged to take action), and/or distracted (talked about something other than the threatening situation). 
Prior to accept of participation all patients were informed about the different support combinations and how these potentially could benefit the patients.

In all groups: a hospital porter transferred the patient in bed from the ward to the operating ward. Five to ten minutes later, a nurse anesthetist came and stayed with the patient throughout the patient's remaining period on the ward an in theatre. The nurse anesthetist had a list of questions to put to the patient, inserted a drip and assisted the anesthesiologist in inserting, if appropriate, an epidural catheter. The operating nurse and the surgeon would stop by to ask some questions, which is required by law, and would leave. In the operating theatre, the operating nurse and the nurse anesthetist would help the patient to be warm and to lie in a way that would avoid pressure sores. All those involved stayed with the patient until she was heavily sedated.

The differences between groups:

1. Standard care: a surgical nurse met the patient on arrival on the operating ward, and stayed with the patient until she was sedated at the operating theatre. As standard, we have long had an idea of this care as optimal.

2. The Ward Model: a nurse known to the patient accompanied her to the operating ward. A project nurse with several years of experience in gynecological cancer care met the patient at the outpatient clinic prior to scheduled surgery in order to establish a connection and to answer questions. On the day of surgery, approximately 15 minutes before transfer from the gynecology ward, the same project nurse visited the patient again and accompanied her to the operating ward, and into the operating theatre. This care combination might be superior, as a known nurse might be beneficial for patients.

3. The Caregiver Model: a relative accompanied the patient to the operating ward.

On the day of surgery, a close relative of the patient's choosing was prepared to follow the patient. (S)he was shown a photo of the operating theatre, was asked to put on protective clothing, and was informed to leave the operating theatre quietly once the patient was heavily sedated. The close relative accompanied the patient to the operating ward and into the operating theatre, and acted according to the patient's wishes and as appropriate to the situation. As a close relative know the patient and visa versa, it might be beneficial to patients to have a close relative by their side at the theatre.

4. The Anaesthesia Model: only the nurse anesthetist attended to the patient 5 - 10 minutes after arrival on the operating ward. The nurse anesthetist and the operating nurse accompanied the patient from the operating ward into the operating theatre. In this care combination the nurse anesthetist and the patient had undisturbed time to establish a relationship, which might be beneficial to patients, as the nurse anesthetist would be the one keeping a special eye on the patient when she would become sedated.

\subsection{Outcomes}

\section{Patient measures and data collection}

The primary outcome was a change in nervousness from admission to immediately prior to anesthesia and cancer surgery. Patients expressed their nervousness intensity as a VAS (Visual Analog Scale) score, ranging from zero to ten, where zero meant not at all nervous and ten meant the most nervous the patient thought she could ever be. This measure was collected with one decimal upon admission (primarily noted by the same secretary for all patients) and immediately before being anaesthetized (noted by the nurse anesthetist who was present). The VAS score was tested in the study population before study start $(n=20)$, and a clinically meaningful difference was stated to be $0.9-1.0$. The secondary outcome was global satisfaction at discharge, measured by use of a questionnaire filled in by the patients immediately before discharge and handed to a nurse in a sealed envelope. The questionnaire had a four-point Likert scale, including the possibility to choose "don't know" and included the five items: global questions regarding information received practical help, support, surgery and medicine, as well as the overall impression of the hospital visit. It was qualitatively validated in the study population $(n=12)$ before study start using a think-aloud test with silent observations, retrospective interviewing, and a small correction to one question after testing on the first four patients [29].

Patient characteristics and time spent

Specific patient characteristics were given by the patients before randomization and collected later from the electronic patient journal. The nurses involved measured time spent on support that was in addition to that provided by the nurse anesthetist in each group.

\subsection{Sample Size}

Based on a prior study [10], we assumed a mean change of three on the VAS scale in the standard care group, 
and a common standard deviation of two. With these assumptions, we calculated that, with 64 patients in each group, we would have $80 \%$ power at the two-sided $5 \%$ level to detect a difference of at least one in mean change of nervousness.

\subsection{Randomization and Masking}

Participants were assigned to one of the four groups using simple randomization via a computer-generated random number list that was printed out and placed in numbered sealed envelopes by the first author. Nurses at the outpatient clinic collected written informed consent, and telephoned the study nurse who allocated patients to a group using the next numbered sealed envelopes. Patients became participants as soon as the envelope was opened. The nature of the interventions made it impossible to mask either patients or healthcare professionals. The statistician was masked until the analyses and interpretations were completed.

\subsection{Control of Complex Intervention}

All the nurses were regularly verbally incited to keep the interventions as described and to report immediately, if any deviations were observed. Moreover, first author made three to five minutes semi-structured interviews with random participants in all groups with the prompt: Please describe for me, the care you received before anesthesia.

\subsection{Statistical Analyses}

Specific patient characteristics were summarized by descriptive statistics number and percentage for categorical parameters and mean, range of scores, and standard deviation for continuous parameters. VAS score at admission and immediately prior to surgery were summarized, together with the corresponding change. The primary analysis was by linear regression of the difference in VAS score adjusted for group and baseline score, with the standard care group as reference. The difference in change in VAS score between the groups is given by the mean, together with the 95\% CI. The normality assumption of the difference was checked by visual inspection of the quantile-quantile plot. The primary analysis was on the full analysis set, i.e. only those with two VAS score measurements. Additionally, we assumed that missing scores were "Missing At Random" i.e. the missing values did not depend on unobserved data. Under this assumption, the missing values were imputed using multiple-imputation with a model containing group and baseline value. Linear regression was performed, including the imputed values of the difference adjusted for group and baseline value. Furthermore, we repeated the primary analysis with the Minimal Model as reference. The questionnaire scores were summed and both a KruskalWallis equality-of-populations rank test and pairwise Wilcoxon rank sum tests were performed. Stata 13.1 StataCorp LP, College Station TX USA was used for all statistical analyses.

\subsection{Ethical Issues}

Before randomization, patients were informed of the standard care to non-participants, including the possibility to be accompanied by a relative up to (but not into) the operating theatre. The study number at the Biomedical Research Committee System Act at the Scientific Committee for Southern Region in Denmark is S-2008200041, and the study adheres to the Declaration of Helsinki [30] and the Ethical Guidelines for Nursing Research in the Nordic Countries [31]. It was ethical acceptable to ask patients about their nervousness right before anesthesia as this theme had been addressed to the patients earlier, the question was asked friendly by the nurse anesthetist, and it is not necessarily desirable to remove nervousness entirely before sedation [11] [22].

\section{Results}

In total, 1116 patients were assessed for eligibility from December 2008. In May 2012, the desired sample size was reached and inclusion ceased. In total, 350 patients provided written informed consent and were randomized (Figure 1). Among the non-participants, many were offered minimal invasive surgery, some stated that they did not have relatives, several declined to participate without giving a reason, and some did not want to rely on help from relatives. Of those randomized, 13 did not want to participate in the end (due to overwhelming developments in their disease or unspecified situations), and 42 experienced changes in treatment plan (to minimal inva- 


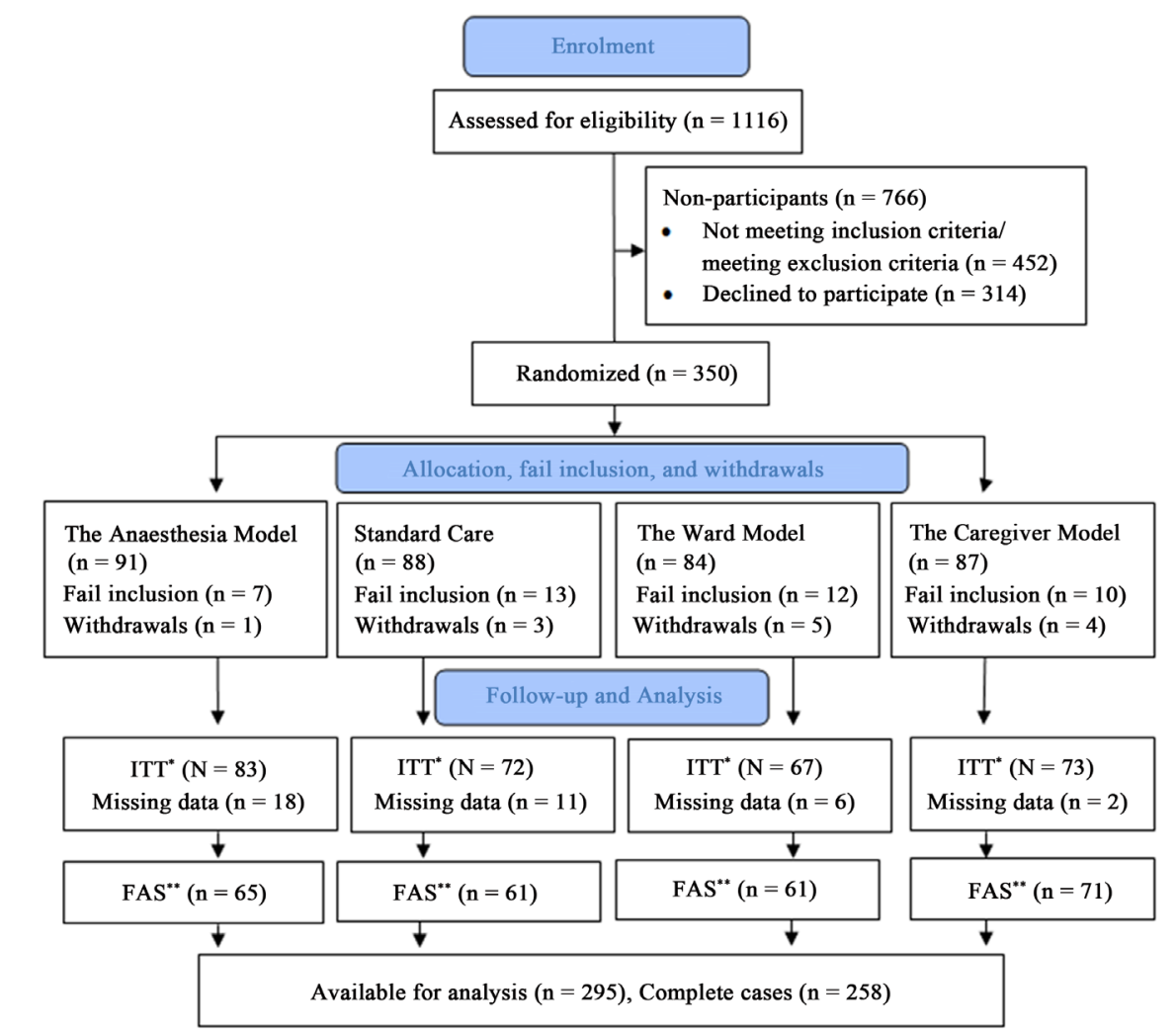

Figure 1. Flow chart. ${ }^{*}$ ITT: Intention to treat, ${ }^{* *}$ FAS: Full Analysis set.

sive surgery or surgery at another hospital). A total of 295 patients provided specific characteristics and these were well balanced across the randomization groups (Table 1). All 295 patients provided a VAS score on admission, and approximately 1.5 days passed between this and the next VAS measures. A total of 37 patients were lost to follow-up, primarily due to business on the ward and premedication given before the VAS evaluation, leaving 258 as complete cases. Patients were in 73 cases follow by a relative of their choice, which were mainly a husband or a daughter. Only few had chosen a friend to follow them. The interventions were delivered consistently apart from four cases where other nurses reported the care to be not as attentive as it could be (one in the ward model and one in standard care) or the care could not be delivered by the same nurse at the outpatient clinic and in the ward (two in the ward model). All interviewed patients $(n=30)$ described the right care according to their allocation, and a few of those receiving the caregiver model commented, that they were surprised about their relatives reaction which could be both positive and negative.

Descriptive statistics for VAS of nervousness reveals no apparent clinically relevant difference on admission (Table 2). We observed a mean increase in nervousness in all four groups. The largest increase related to the Anesthesia Model, where only a nurse anesthetist was present. This is depicted, for illustration purposes only, by the regression lines in Figure 2. Patients who received supportive care in the form of the Ward Model exhibited the greatest benefit, with a mean difference in change in nervousness of -0.38 [CI: -1.140 to 0.385 ] $p=0.330$, but no experimental model proved to be superior to standard care with statistical significance or clinical relevance. The Caregiver Model achieved a mean difference of 0.23 [CI: -0.498 to 0.967 ] $p=0.528$, and the Anesthesia Model achieved a mean difference of 1.05 [CI: 0.298 to 1.794] $p=0.006$. In the additional analysis, the Anesthesia Model was found to be significantly inferior to all the other care combinations. However, in those receiving support from the Caregiver Model, the difference was not clinically relevant: -0.81 [CI: -1.532 to $-0.011] p=0.027$. The Ward Model achieved a mean difference of 1.42 [CI: -2.174 to -0.674$] p<0.001$. When we performed an analysis for robustness by multiple imputations, no substantial changes were found (data not shown). With regard to patient satisfaction, we found a similar picture. No experimental models proved superior to standard care (Table 3), but in the additional analysis, the Anesthesia Model proved significantly inferior to both standard care $(p=0.013)$, the Ward Model $(p \leq 0.001)$, and the Caregiver Model $(p=0.004)$. The 


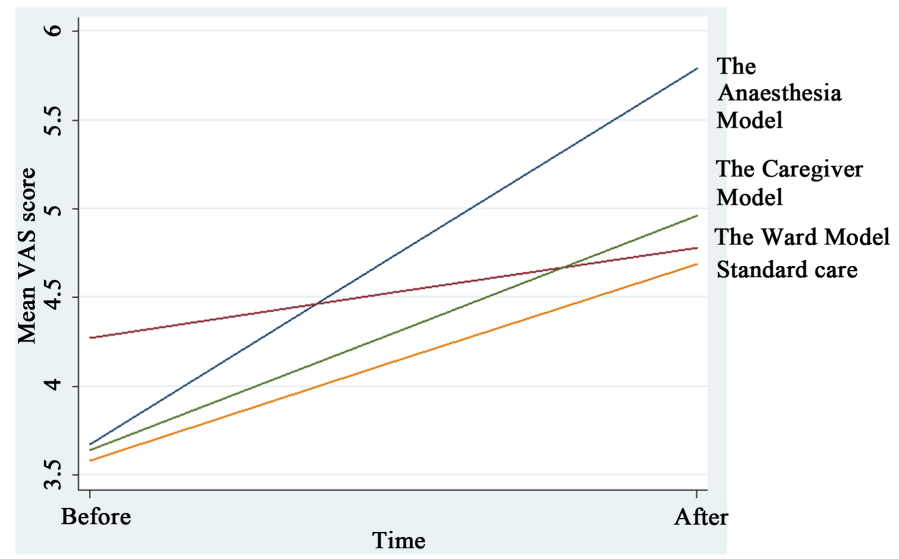

Figure 2. Regression lines for differences in Visual Analogue Score (VAS) in the four groups at the time before and after intervention.

Table 1. Patient characteristics at admission and at discharge, and the staging.

\begin{tabular}{|c|c|c|c|c|}
\hline \multirow{2}{*}{ Characteristics at admission in groups } & The Anaesthesia Model & Standard care & The Ward Model & The Caregiver Model \\
\hline & $\mathrm{N}=83, \mathrm{n}(\%)$ & $\mathrm{N}=72, \mathrm{n}(\%)$ & $\mathrm{N}=67, \mathrm{n}(\%)$ & $\mathrm{N}=73, \mathrm{n}(\%)$ \\
\hline Live alone & $14(16.9)$ & $12(16.7)$ & $12(17.9)$ & $15(20.6)$ \\
\hline Under 60 years of age & $40(48.2)$ & $38(52.8)$ & $31(46.3)$ & $41(56.2)$ \\
\hline Previous surgery & $53(63.9)$ & $51(70.8)$ & $51(76.1)$ & $53(72.6)$ \\
\hline Diagnosed cancer before surgery & $37(44.6)$ & $31(43.1)$ & $24(35.8)$ & 25 (34.3) \\
\hline \multicolumn{5}{|l|}{ Characteristics at discharge } \\
\hline Benign diagnosis before discharge & $13(15.7)$ & $6(8.3)$ & $13(19.4)$ & $15(20.6)$ \\
\hline Postoperative infection or reoperation & $8(9.6)$ & $8(11.1)$ & $7(10.5)$ & $10(13.7)$ \\
\hline \multicolumn{5}{|l|}{ Diagnosis } \\
\hline Tumour delimited to the affected organ & $8(9.6)$ & $5(6.9)$ & $6(9.0)$ & $5(6.9)$ \\
\hline Tumour is spread outside the affected organ & $59(51.8)$ & $47(48.6)$ & $38(47.8)$ & $48(49.3)$ \\
\hline
\end{tabular}

Table 2. Distribution of the Visual Analogue Score $\left(\mathrm{VAS}^{\mathrm{a}}\right)$ of nervousness and the differences between them within the original assigned groups.

\begin{tabular}{|c|c|c|c|c|}
\hline & The Anesthesia Model & Standard care & The Ward Model & The Caregiver Model \\
\hline & N (range) Mean, SD & $\mathrm{N}$ (range) Mean, SD & N (range) Mean, SD & N (range) Mean, SD \\
\hline \multicolumn{5}{|c|}{ Hospitalization } \\
\hline FAS $^{\mathrm{b}}$ & 65 (0 to 10$) 3.7,2.5$ & 61 (0 to 10$) 3.6,2.8$ & 61 (0 to 10$) 4.3,3.1$ & 71 (0 to 10$) 3.6,2.8$ \\
\hline $\mathrm{ITT}^{\mathrm{c}}$ & 83 (0 to 10$) 3.8,2.5$ & $72(0$ to 10$) 3.5,2.7$ & 67 (0 to 10$) 4.2,3.1$ & 73 (0 to 10$)$ 3.6, 2.8 \\
\hline \multicolumn{5}{|c|}{ Preoperative } \\
\hline FAS $^{\mathrm{b}}$ & 65 (0 to 8.2) 5.8, 2.9 & 61 (0 to 10$) 4.7,2.7$ & $61(0$ to 10$) 4.8,3.0$ & $71(0.5$ to 10$) 5.0,2.8$ \\
\hline $\mathrm{ITT}^{\mathrm{c}}$ & 65 (0 to 10$) 5.8,2.9$ & 61 (0 to 10$) 4.7,2.7$ & 61 (0 to 10$) 4.8,3.0$ & 71 (0.5 to 10$) 5.0,2.8$ \\
\hline \multicolumn{5}{|c|}{ Difference } \\
\hline FAS $^{\mathrm{b}}$ & $65(-2$ to 8.2$) 2.1,2.5$ & 61 (-4.9 to 8.2) 1.1, 2.3 & $61(-4.4$ to 6$) 0.5,2.0$ & $71(-5.2$ to 6.4$) 1.3,2.4$ \\
\hline ITT $^{\mathrm{c}}$ & 65 (-2 to 8.2) 2.1, 2.5 & $61(-4.9$ to 8.2$) 1.1,2.3$ & $61(-4.4$ to 6$) 0.5,2.0$ & $71(-5.2$ to 6.4$) 1.3,2.4$ \\
\hline
\end{tabular}

${ }^{\mathrm{a}}$ VAS score of nervousness is from 0 to 10 , with 0 as no nervousness at all and 10 as the most extreme nervousness patients could ever think of, ${ }^{b}$ FAS: Full Analysis Set, ${ }^{\mathrm{ITT}}$ : Intention to Treat. 
Table 3. Distribution of patient satisfaction score in the four original assigned groups and differences between groups.

\begin{tabular}{cccccccc}
\hline & & & & & \multicolumn{2}{c}{$p$-value } \\
\cline { 6 - 7 } & $\mathrm{N}$ & Mean $^{\mathrm{a}}$ & $\mathrm{SD}$ & Median & & Compared to the Anaesthesia Model & Compared to standard care \\
\hline The Anaesthesia Model & 83 & 11.4 & 5.5 & 14 & & 0.013 \\
Standard care & 72 & 13.1 & 4.1 & 15 & 0.013 & 0.351 \\
The Ward Model & 67 & 13.9 & 2.7 & 15 & 0.001 & 0.850 \\
The Caregiver Model & 73 & 13.8 & 2.7 & 15 & & \\
\hline
\end{tabular}

${ }^{\mathrm{a}}$ Score $\min =0, \max =15$.

Anesthesia Model was the most economically efficient, as it involved no additional time to that spent by the nurse anesthetist, while, for standard care, the Ward Model and the Caregiver Model, respectively, 35, 57, and 6 additional minutes per patient were spent by staff.

\section{Discussion}

We investigated the effect of different healthcare combinations and the involvement of a relative on the nervousness of cancer patients before anesthesia and cancer surgery and we were not able to show that any of the tested interventions were better than standard care. In our additional analyses, standard care, the Ward Model and the Caregiver Model proved significantly better than the Anesthesia Model on both measures: global satisfaction at discharge and VAS of nervousness before sedation and surgery. However, a clinically relevant improvement was reached only by standard care and the Ward Model. Patients' nervousness was not eradicated, but an increase in nervousness was to some degree counteracted. Preoperative anxiety and recovery have been in focus in research for more than fifty years. Within the last two decades, reviews acknowledge that, a reduction of preoperative anxiety to zero would not necessarily be of benefit to patients [11] [22]. Preoperative anxiety is, nevertheless, a good predictor of recovery [11] [13] [14] [32] [33], and a recent systematic review recommends a reduction in higher levels of anxiety before sedation for surgery for a life-threatening disease [34]. Because anxiety level is influenced by personality characteristics [35], a recommended preoperative anxiety level would be misleading. Our study adds more scientifically tested care combinations to support patients in counteracting an increase in preoperative anxiety. The procedures carried out by the nurse anesthetist could be painful. Moreover, in our study, the anesthetist came to the patient five to ten minutes after the patient arrived on the operating ward. Pain inflicted by healthcare professionals might provoke anxiety, and in our unconscious mind, pain might be linked to threat and danger [36]. Research on patients' experiences of dialogues prior to, during and after surgery with the same nurse, however, revealed that patients considered the talks they had and the continuity to be anxiety-reducing [37] [38] and even that they "prevented and alleviated suffering in surgical procedures” [37]. This idea is supported in a study about children's healthcare. It is less the case that the patient suffers pain from the actual procedures conducted, but from the environment in which they take place [39]. The inherent waiting time at the operating ward before the anesthetist nurse showed up may have contributed to patients’ perception of the situation. This is supported by research performed by Cobley et al., who interviewed 124 patients by means of a 16-item questionnaire within 36 hours of surgery and found that arrival at the operating ward was a distressing time for patients, and for some it was even unbearable [40]. Having someone to talk to during the perioperative period is preferred by females [27], and females might indeed benefit by not being left alone at the final preoperative stage. However, we lack research on adult patients' experiences in general, the effects of unpleasant or painful preoperative procedures, and being left alone on the operating ward.

We found no statistical or clinically relevant difference between standard care and the Ward Model or the Caregiver Model. These interventions both offered ongoing attention and care from the time before leaving the ward and until the patient was anaesthetized. In this way, support was provided throughout the period that Coleby et al. identified as specifically distressing before surgery: waiting on the ward and being transferred to, and arriving at, the operating ward [40]. Moreover, the patients who received these support interventions had the opportunity to make a connection with their respective supporters, which might also be beneficial for patients [20] [25]. However, compared to standard care, the benefit for patients was not statistically significant or clinically relevant in counteracting an increase in nervousness and did not show an increase in global satisfaction 
with the healthcare. It is notable that compared to the Anesthesia Model in the additional analyses; the Caregiver Model did not result in clinically relevant changes in patients' experienced nervousness. Relatives might have more personal strength than patients, but new research has found a link between the level of anxiety in cancer patients and their relatives [41]. Moreover, a new systematic review did not find a convincing effect of family caregivers' supportive care in cancer [42]. Therefore, it is not recommended to rely fully on supportive care from relatives in the preoperative period.

\section{Strengths and Limitations}

We planned the sample size assuming a standard deviation of two. Evidently, this was optimistic for some groups (Table 2). Thus, the study is slightly under-powered. However, apart from the Minimal Group, none of the experimental groups show clinically relevant differences compared to the standard care group. Hence, higher power would not be likely to alter the clinical conclusions.

The satisfaction questionnaire used was only qualitatively validated. However, the few questions were validated in the study population ahead of study start. Both of the patient measures were based solely on self-report and therefore influenced by personality. Given the size of the study, we can be fairly confident that any unobserved characteristics were well-balanced across the groups. However, we acknowledge that there is some potential for bias because our randomization was not blinded to the patients, the healthcare professionals or the relatives. Patients might have been more nervous by knowing they were allocated to the model with only one supporting nurse. Patients were, however, informed about the possible benefits of all the care combinations, and one good care relation is expected to be enough [20] [21]. Moreover, following this logic, patients who knew they were to receive care from an additional person and even be followed from the ward might have been even less nervous, but we did not observe this. The healthcare professionals could have promoted their own intervention and disturbed others', but this was not reported. On the contrary, others performance was reported if it was not as attentive as possible judged by their healthcare professional co-workers. At the study site, each nurse's primary aim was to strive to help the individual patients as well as possible, and the study's aim was secondary to this, which is reflected in the missing VAS scores from the operating room. The fact that these are missing, of course, constitutes a limitation in its own right, but the number of complete cases is still convincing, and the robustness analysis did not hint at any problems with reliability. Our interventions ran over more years. The intervention did not change, but the context changed slightly with a few changes in staff, and increased offers of minimal invasive surgery which excluded such patients and leaved those with larger tumors as participants in our study. However, all changes would have affected even in the four arms, due to the study design. The interventions were complex and it was not possible to control whether the best possible anxiety reduction strategy was used in the specific interactions. However, we expected that the healthcare professionals would need to be free to use their knowledge and skills to adapt care to suit individual patients' needs [27] [43]. Our approach was to stay as close as possible to usual clinical practice and this enhanced the ecological validity of the study, and, consequently, its external validity [44]. Of females acceptable for inclusion, $47 \%$ declined to participate. As is inherent in almost all such research, we may therefore have included only the strongest.

Previous studies report that females have a greater tendency to have preoperative anxiety, a tendency to higher anxiety, and more females than males prefer to have a partner by their side in the preoperative period [26][28]. Eventually generalizability to male patient populations should therefore be done with great caution.

\section{Conclusion}

Supportive care by a surgery nurse, from the time of arrival at the operating ward, and by a nurse anesthetist, from 5 - 10 minutes after the arrival and until the patient has been anesthetized, will help female cancer patients to counteract an increase in preoperative nervousness and feel satisfied at discharge. The support and company of a ward nurse from ten minutes before leaving the ward and until the patient is anesthetized provide a similar level of benefit. However, support from a surgery nurse and a nurse anesthetist might be attractive to offer as standard, because this is the most time efficient of the four care combinations. Relatives might, to some degree, be helpful in alleviating female patients’ preoperative suffering due to nervousness, but it is not recommended at any time to rely fully on their support. Furthermore, the sole support of a nurse anesthetist from 5 - 10 minutes after arrival at the operating ward is not recommended. How nurse anesthetists’ procedures and patients’ time alone on the operating ward affect adult patients in general should be the focus of further research. 


\section{Acknowledgements}

We thank the patients and the relatives who participated in this study. Moreover, we thanks Jette Johansen, Annette Henriksen, Inger Juhl and Kristian Kidholm who contributed to the study's conception and we acknowledge the important collaboration in randomization and data collection with nurse anesthetists, surgery nurses, ward nurses, and the secretary where the study took place. Lorna Campbell copy-edited this article. The study was financially supported by non-partisan funds: The Tryg Foundation and Sister Marie Dalgaard’s Foundation.

\section{References}

[1] Carr, E., Brockbank, K., Allen, S. and Strike P. (2006) Patterns and Frequency of Anxiety in Women Undergoing Gynaecological Surgery. Journal of Clinical Nursing, 15, 341-352. http://dx.doi.org/10.1111/j.1365-2702.2006.01285.x

[2] Thygesen, M.K., Pedersen, B.D., Kragstrup, J., Wagner, L. and Mogensen, O. (2011) Utilizing a New Graphical Elicitation Technique to Collect Emotional Narratives Describing Disease Trajectories. The Qualitative Report, 16, 596608. http://nsuworks.nova.edu/cgi/viewcontent.cgi?article=1076\&context=tqr

[3] Mackenzie, J.W. (1989) Daycase Anaesthesia and Anxiety. A Study of Anxiety Profiles amongst Patients Attending a Day Bed Unit. Anaesthesia, 44, 437-440.

[4] Mitchell, M. (2003) Patient Anxiety and Modern Elective Surgery: A Literature Review. Journal of Clinical Nursing, 12, 806-815. http://dx.doi.org/10.1046/j.1365-2702.2003.00812.x

[5] Grieve, R.J. (2002) Day Surgery Preoperative Anxiety Reduction and Coping Strategies. British Journal of Nursing, 11, 670-678. http://dx.doi.org/10.12968/bjon.2002.11.10.670

[6] Mertz, B.G., Bistrup, P.E., Johansen, C., Dalton, S.O., Deltour, I. and Kehlet, H. (2012) Psychological Distress among Women with Newly Diagnosed Breast Cancer. European Journal of Oncology Nursing: The Official Journal of European Oncology Nursing Society, 16, 439-443. http://dx.doi.org/10.1016/j.ejon.2011.10.001

[7] Rosen, S., Svensson, M. and Nilsson, U. (2008) Calm or Not Calm: The Question of Anxiety in the Perianesthesia Patient. Journal of Perianesthesia Nursing: Official Journal of the American Society of PeriAnesthesia Nurses/American Society of PeriAnesthesia Nurses, 23, 237-246. http://dx.doi.org/10.1016/j.jopan.2008.05.002

[8] Haugen, A.S., Eide, G.E., Olsen, M.V., Haukeland, B., Remme, A.R. and Wahl, A.K. (2009) Anxiety in the Operating Theatre: A Study of Frequency and Environmental Impact in Patients Having Local, Plexus or Regional Anaesthesia. Journal of Clinical Nursing, 18, 2301-2310. http://dx.doi.org/10.1111/j.1365-2702.2009.02792.x

[9] Oxford Dictionaries (2015) Oxford University Press. http://www.oxforddictionaries.com

[10] Videbech, M., Carlsson, P.S., Jensen, N.C. and Videbech, P. (2003) [Measuring of Preoperative Anxiety by Three Self-Reporting Scales: State Trait Anxiety Inventory, Symptoms CheckList 92 and Visual Analogue Scale]. Ugeskrift for Laeger, 165, 569-574.

[11] Munafo, M.R. and Stevenson, J. (2001) Anxiety and Surgical Recovery. Reinterpreting the Literature. Journal of Psychosomatic Research, 51, 589-596. http://dx.doi.org/10.1016/S0022-3999(01)00258-6

[12] Markland, D. and Hardy, L. (1993) Anxiety, Relaxation and Anaesthesia for Day-Case Surgery. British Journal of Clinical Psychology, 32, 493-504. http://dx.doi.org/10.1111/j.2044-8260.1993.tb01085.X

[13] Kil, H.K., Kim, W.O., Chung, W.Y., Kim, G.H., Seo, H. and Hong, J.Y. (2012) Preoperative Anxiety and Pain Sensitivity Are Independent Predictors of Propofol and Sevoflurane Requirements in General Anaesthesia. British Journal of Anaesthesia, 108, 119-125. http://dx.doi.org/10.1093/bja/aer305

[14] Li, C., Carli, F., Lee, L., Charlebois, P., Stein, B. and Liberman, A.S. (2013) Impact of a Trimodal Prehabilitation Program on Functional Recovery after Colorectal Cancer Surgery: A Pilot Study. Surgical Endoscopy, 27, $1072-1082$. http://dx.doi.org/10.1007/s00464-012-2560-5

[15] Teasdale, K. (1995) Theoretical and Practical Considerations on the Use of Reassurance in the Nursing Management of Anxious Patients. Journal of Advanced Nursing, 22, 79-86. http://dx.doi.org/10.1046/j.1365-2648.1995.22010079.x

[16] Nilsson, U., Rawal, N., Enqvist, B. and Unosson, M. (2003) Analgesia Following Music and Therapeutic Suggestions in the PACU in Ambulatory Surgery: A Randomized Controlled Trial. Acta Anaesthesiologica Scandinavica, 47, 278283. http://dx.doi.org/10.1034/j.1399-6576.2003.00064.x

[17] Ayyadhah Alanazi, A. (2014) Reducing Anxiety in Preoperative Patients: A Systematic Review. British Journal of Nursing, 23, 387-393. http://www.magonlinelibrary.com/doi/pdf/10.12968/bjon.2014.23.7.387

[18] Jlala, H.A., French, J.L., Foxall, G.L., Hardman, J.G. and Bedforth, N.M. (2010) Effect of Preoperative Multimedia Information on Perioperative Anxiety in Patients Undergoing Procedures under Regional Anaesthesia. British Journal of Anaesthesia, 104, 369-374. http://dx.doi.org/10.1093/bja/aeq002

[19] Lin, S.Y., Huang, H.A., Lin, S.C., Huang, Y.T., Wang, K.Y. and Shi, H.Y. (2016) The Effect of an Anaesthetic Patient 
Information Video on Perioperative Anxiety: A Randomised Study. European Journal of Anaesthesiology, 33, 134-139. http://dx.doi.org/10.1097/EJA.0000000000000307

[20] Bowlby, J. (1989) The Making and Breaking of Affectional Bonds. Routledge, London.

[21] Thygesen, M.K., Pedersen, B.D., Kragstrup, J., Wagner, L. and Mogensen, O. (2011) Benefits and Challenges Perceived by Patients with Cancer When Offered a Nurse Navigator. International Journal of Integrated Care, 11, e130. http://www.ncbi.nlm.nih.gov/pmc/articles/PMC3225241/pdf/ijic2011-2011130.pdf

[22] Salmon, P. (1993) The Reduction of Anxiety in Surgical Patients: An Important Nursing Task or the Medicalization of Preparatory Worry? International Journal of Nursing Studies, 30, 323-330. http://dx.doi.org/10.1016/0020-7489(93)90104-3

[23] Guo, P. (2015) Preoperative Education Interventions to Reduce Anxiety and Improve Recovery among Cardiac Surgery Patients: A Review of Randomised Controlled Trials. Journal of Clinical Nursing, 24, 34-46. http://onlinelibrary.wiley.com/doi/10.1111/jocn.12618/epdf http://dx.doi.org/10.1111/jocn.12618

[24] Rudolfsson, G., von Post, I. and Eriksson, K. (2007) The Perioperative Dialogue: Holistic Nursing in Practice. Holistic Nursing Practice, 21, 292-298. http://dx.doi.org/10.1097/01.HNP.0000298613.40469.6c

[25] Lindwall, L. and von Post, I. (2009) Continuity Created by Nurses in the Perioperative Dialogue-A Literature Review. Scandinavian Journal of Caring Science, 23, 395-401. http://dx.doi.org/10.1111/j.1471-6712.2008.00609.x

[26] Karanci, A.N. and Dirik, G. (2003) Predictors of Pre- and Postoperative Anxiety in Emergency Surgery Patients. Journal of Psychosomatic Research, 55, 363-369. http://dx.doi.org/10.1016/S0022-3999(02)00631-1

[27] Mitchell, M. (2013) Anaesthesia Type, Gender and Anxiety. Journal of Perioperative Practice, 23, 41-47.

[28] Blais, M.C., St-Hilaire, A., Fillion, L., De Serres, M. and Tremblay, A. (2014) What to Do with Screening for Distress Scores? Integrating Descriptive Data into Clinical Practice. Palliative \& Supportive Care, 12, 25-38. http://dx.doi.org/10.1017/S1478951513000059

[29] Drennan, J. (2003) Cognitive Interviewing: Verbal Data in the Design and Pretesting of Questionnaires. Journal of Advanced Nursing, 42, 57-63. http://dx.doi.org/10.1046/j.1365-2648.2003.02579.x

[30] WMA Declaration of Helsinki (2013) Ethical Principles for Medical Research Involving Human Subjects. http://www.wma.net/en/30publications/10policies/b3/index.html

[31] Northern Nurses' Federation (2003) Ethical Guidelines for Nursing Research in the Nordic Countries. Nordic Journal of Nursing Research \& Clinical Studies/Vaard i Norden, 23, 1-5.

[32] Granot, M. and Ferber, S.G. (2005) The Roles of Pain Catastrophizing and Anxiety in the Prediction of Postoperative Pain Intensity: A Prospective Study. The Clinical Journal of Pain, 21, 439-445. http://dx.doi.org/10.1097/01.ajp.0000135236.12705.2d

[33] Pearson, S., Maddern, G.J. and Fitridge, R. (2005) The Role of Pre-Operative State-Anxiety in the Determination of Intra-Operative Neuroendocrine Responses and Recovery. British Journal of Health Psychology, 10, 299-310. http://dx.doi.org/10.1348/135910705X26957

[34] McKenzie, L.H., Simpson, J. and Stewart, M. (2010) A Systematic Review of Pre-Operative Predictors of Post-Operative Depression and Anxiety in Individuals Who Have Undergone Coronary Artery Bypass Graft Surgery. Psychology, Health \& Medicine, 15, 74-93. http://dx.doi.org/10.1080/13548500903483486

[35] King, F.J., Heinrich, D.L., Stephenson, R.S. and Spielberger, C.D. (1976) An Investigation of the Causal Influence of Trait and State Anxiety on Academic Achievement. Journal of Educational Psychology, 68, 330-334. http://dx.doi.org/10.1037/0022-0663.68.3.330

[36] Collen, M. (2014) Pain and Treatment from a Human Primate Perspective. Journal of Pain \& Palliative Care Pharmacotherapy, 28, 152-157. http://dx.doi.org/10.3109/15360288.2014.911237

[37] Lindwall, L., von Post, I. and Bergbom, I. (2003) Patients' and Nurses’ Experiences of Perioperative Dialogues. Journal of Advanced Nursing, 43, 246-253. http://dx.doi.org/10.1046/j.1365-2648.2003.02707.x

[38] Rudolfsson, G., Hallberg, L.R.M., Ringsberg, K.C. and von Post, I. (2003) The Nurse Has Time for Me: The Perioperative Dialogue from the Perspective of Patients. Journal of Advanced Perioperative Care, 1, 77-84.

[39] Rennick, J.E., Johnston, C.C., Dougherty, G., Platt, R. and Ritchie, J.A. (2002) Children’s Psychological Responses after Critical Illness and Exposure to Invasive Technology. Journal of Developmental and Behavioral Pediatrics: JDBP, 23, 133-144. http://dx.doi.org/10.1097/00004703-200206000-00002

[40] Cobley, M., Dunne, J.A. and Sanders, L.D. (1991) Stressful Pre-Operative Preparation Procedures. The Routine Removal of Dentures during Pre-Operative Preparation Contributes to Pre-Operative Distress. Anaesthesia, 46, 10191022. http://dx.doi.org/10.1111/j.1365-2044.1991.tb09913.x

[41] Cormio, C., Romito, F., Viscanti, G., Turaccio, M., Lorusso, V. and Mattioli, V. (2014) Psychological Well-Being and 
Posttraumatic Growth in Caregivers of Cancer Patients. Frontiers in psychology, 5, 1342.

http://dx.doi.org/10.3389/fpsyg.2014.01342

http://www.ncbi.nlm.nih.gov/pmc/articles/PMC4238371/pdf/fpsyg-05-01342.pdf

[42] Griffin, J.M., Meis, L.A., MacDonald, R., Greer, N., Jensen, A. and Rutks, I. (2014) Effectiveness of Family and Caregiver Interventions on Patient Outcomes in Adults with Cancer: A Systematic Review. Journal of General Internal Medicine, 29, 1274-1282. http://dx.doi.org/10.1007/s11606-014-2873-2

[43] Stoddard, J.A., White, K.S., Covino, N.A. and Strauss, L. (2005) Impact of a Brief Intervention on Patient Anxiety Prior to Day Surgery. Journal of Clinical Psychology in Medical Settings, 12, 99-110. http://link.springer.com/article/10.1007/s10880-005-3269-6\#page-1 http://dx.doi.org/10.1007/s10880-005-3269-6

[44] Bowling, A. (2002) Research Methods in Health. Investigating Health and Health Services. 2nd Edition, Open University Press, Maidenhead. 